\title{
Sources of volatile organic compounds and policy implications for regional ozone pollution control in an urban location of Nanjing, East China
}

\author{
Qiuyue Zhao ${ }^{1,2}$, Jun Bi ${ }^{1}$, Qian Liu ${ }^{2}$, Zhenghao Ling ${ }^{3}$, Guofeng Shen ${ }^{4}$, Feng Chen ${ }^{2}$, Yuezhen Qiao ${ }^{2}$, Chunyan $\mathrm{Li}^{2}$, and \\ Zongwei $\mathrm{Ma}^{1}$ \\ ${ }^{1}$ State Key Laboratory of Pollution Control and Resource Reuse, School of the Environment, \\ Nanjing University, Nanjing 210023, China \\ ${ }^{2}$ Jiangsu Key Laboratory of Environmental Engineering, Jiangsu Academy of Environmental Sciences, \\ Nanjing 210036, China \\ ${ }^{3}$ School of Atmospheric Sciences, Sun Yat-sen University, Guangzhou 510275, China \\ ${ }^{4}$ College of Urban and Environmental Sciences, Peking University, Beijing 100871, China
}

Correspondence: Jun Bi (jbi@nju.edu.cn) and Zhenhao Ling (lingzhh3@mail.sysu.edu.cn)

Received: 11 September 2019 - Discussion started: 25 October 2019

Revised: 2 March 2020 - Accepted: 3 March 2020 - Published: 1 April 2020

\begin{abstract}
Understanding the composition, temporal variability and source apportionment of volatile organic compounds (VOCs) is necessary for determining effective control measures to minimize VOCs and their related photochemical pollution. To provide a comprehensive analysis of VOC sources and their contributions to ozone $\left(\mathrm{O}_{3}\right)$ formation in the Yangtze River Delta (YRD) - a region experiencing the highest rates of industrial and economic development in China - we conducted a 1-year sampling exercise using a thermal desorption GC (gas chromatography) system for the first time at an urban site in Nanjing (JAES site). Alkanes were the dominant group at the JAES site, contributing $\sim 53 \%$ to the observed total VOCs, followed by aromatics $(\sim 17 \%)$, acetylene $(\sim 17 \%)$ and alkenes $(\sim 13 \%)$. We identified seasonal variability in total VOCs (TVOCs) with maximum and minimum concentrations in winter and summer, respectively. Morning and evening peaks and a daytime trough were identified in the diurnal VOC patterns. We identified VOC sources using positive matrix factorization (PMF) and assessed their contributions to photochemical $\mathrm{O}_{3}$ formation by calculating the $\mathrm{O}_{3}$ formation potential (OFP) based on the mass concentrations and maximum incremental reactivities of VOCs. The PMF model identified five dominant VOC sources, with highest contributions from diesel vehicular exhaust $(34 \pm 5 \%)$, followed by gasoline vehicular ex-
\end{abstract}

haust $(27 \pm 3 \%)$, industrial emissions $(19 \pm 2 \%)$, fuel evaporation $(15 \pm 2 \%)$ and biogenic emissions $(4 \pm 1 \%)$. The results of the OFP calculation inferred that VOCs from industrial and vehicular emissions were found to be the dominant precursors for OFP, particularly the VOC species of xylenes, toluene and propene, and top priority should be given to these for the alleviation of photochemical smog. Our results therefore highlight that priority should be given to limited VOC sources and species for effective control of $\mathrm{O}_{3}$ formation in Nanjing.

\section{Introduction}

Volatile organic compounds (VOCs) are key precursors of $\mathrm{O}_{3}$ and secondary organic aerosols (SOAs) - a major component of fine particulate matter $\left(\mathrm{PM}_{2.5}\right)$. VOCs significantly contribute to the formation of photochemical smog, atmospheric oxidative capacity, visibility degradation, and global climate (Jenkin and Clemitshaw, 2000; Seinfeld and Pandis, 2006), and some VOCs are also known to be toxic to human health. Therefore, in recent years, much research has focused on the impacts of VOCs due to their influence on atmospheric chemistry and impacts on human health (Shao et al., 2009a, $\mathrm{b}$, and references therein). 
The Yangtze River Delta (YRD) region (ShanghaiJiangsu-Zhenjiang region) is one of the fastest-growing regions in China, having recently undergone rapid urbanization and industrialization. Rapid economic growth has led to increased photochemical smog and elevated concentrations of ground-level $\mathrm{O}_{3}$ and fine particulate matter $\left(\mathrm{PM}_{2.5}\right)$. These conditions have been listed as the most important sources of pollution affecting the population in the YRD region, and they are likely caused by increasing concentrations of VOCs. Therefore, it has been suggested that controlling VOC emissions is necessary for the effective alleviation of photochemical smog (Wang et al., 2009; Zhang et al., 2009; Cai et al., 2010; Kurokawa et al., 2013; Ding et al., 2016).

To further understand VOC characteristics and to develop effective policies towards lowering VOC emissions, a number of sampling campaigns have been conducted to investigate the components, mixing ratios, photochemical reactivity and emissions of VOCs over the YRD region (Cai et al., 2010; An et al., 2014; Mo et al., 2015; Pan et al., 2015; Shao et al., 2016; Xu et al., 2017). For example, based on continuous observation data collected from March 2011 to February 2012, An et al. (2014) identified clear seasonal VOC variability in an industrial area of Nanjing, with maximum and minimum levels observed in summer and winter, respectively. VOC variability was also found to be strongly influenced by industrial emissions. In contrast, Mo et al. (2017) found no difference in VOC chemical compositions between residential, industrial and suburban areas of the coastal industrial city Ningbo. By comparing the emission-based profiles and those extracted from the positive matrix factorization (PMF) model, the petrochemical industry was identified as the highest contributor of ambient VOCs due to the unique industrial structure of Ningbo, which is a coastal city located on the southern wing of the Yangtze River Delta with petrochemical industry as its leading industry (Mo et al., 2015, 2016). Pan et al. (2015) conducted emissions measurements of open biomass burning in the rural area of the YRD region and examined the major contributors to $\mathrm{O}_{3}$ pollution using a box model together with the Regional Atmospheric Chemical Mechanism. Overall, these studies were conducted in industrialized and/or rural areas of the YRD region and demonstrate the contribution of industrial emissions and biomass burning towards ambient VOC levels and their contributions to $\mathrm{O}_{3}$ formation. However, VOC studies in urban areas of the YRD region are limited and could help to improve our understanding of the spatial variability of VOCs and their environmental impact, particularly as stricter policies on VOCs and/or photochemical smog have been implemented since 2013 (Fu et al., 2016). Furthermore, the sampling resolution and sampling duration of these studies were relatively low as the samples were collected using canisters. High-resolution VOC datasets can provide more detailed information on the temporal and spatial variability, source apportionments, and impact factors of VOCs.
In this study, we collected continuous 1-year observational VOC data at an urban site in Nanjing in the YRD region. The seasonal and diurnal characteristics of VOCs were investigated, and their sources were identified and quantified using the PMF model. Furthermore, we used a box model together with the Master Chemical Mechanism (MCM) (version 3.2) to identify the $\mathrm{O}_{3}$-precursor relationships and the contributions of VOC sources to photochemical $\mathrm{O}_{3}$ formation. Our results were compared with VOCs data from other Chinese megacities. Based on these findings, we summarize and propose control strategies to minimize VOC pollution and assess their implications for Nanjing and the wider YRD region. The results provide useful information towards lowering photochemical pollution in the YRD region as well as other regions in China.

\section{Methodology}

\subsection{Sampling campaign}

We continuously measured VOC concentrations from January to December 2016, at an observation station on the rooftop of an office building ( $\sim 80 \mathrm{~m}$ above the ground level) of the Jiangsu Academy of Environmental Science (JAES). There is a waterproof layer on the rooftop of the building, but there was no guarantee that it was made of asphalt. Furthermore, despite this waterproof layer on the rooftop of the building, the interferences of emissions from this layer were believed to be insignificant because (1) the waterproof layer was covered a the layer of concrete, which was further covered with a layer of ceramic tile; (2) the building was built 3 years before the sampling campaign was started; and (3) it had been documented that the VOCs emitted from asphalt mainly included benzene, toluene, ethylbenzene and xylene (Gardiner and Lange, 2005). However, the levels of benzene, toluene, ethylbenzene, $m / p$-xylene and $o$-xylene were lower than those observed in other urban, industrial and rural environments in different regions (Sect. 3.1, Zhang et al., 2012; An et al., 2014, 2015; Mo et al., 2015, 2017; He et al., 2019). (4) The sampling inlet was about $2-3 \mathrm{~m}$ above the rooftop of the building.

The station is located in an urban area of Nanjing, and it is surrounded by heavy road traffic, residential buildings, a plant and flower market, and several auto repair shops (Fig. 1). Nanjing, located in the western part of the YRD region, is one of the most urbanized and industrialized areas in the world, and consequently it experiences severe air pollution. The site is located downwind of both Nanjing city center and the wider YRD region (Zhao et al., 2017; Zhou et al., 2017), and it is therefore ideally placed to determine the combined impacts of VOCs from both local and regional atmospheric pollution.

Fifty-six VOC species including alkanes, alkenes, aromatics and acetylene were measured at $1 \mathrm{~h}$ intervals using 


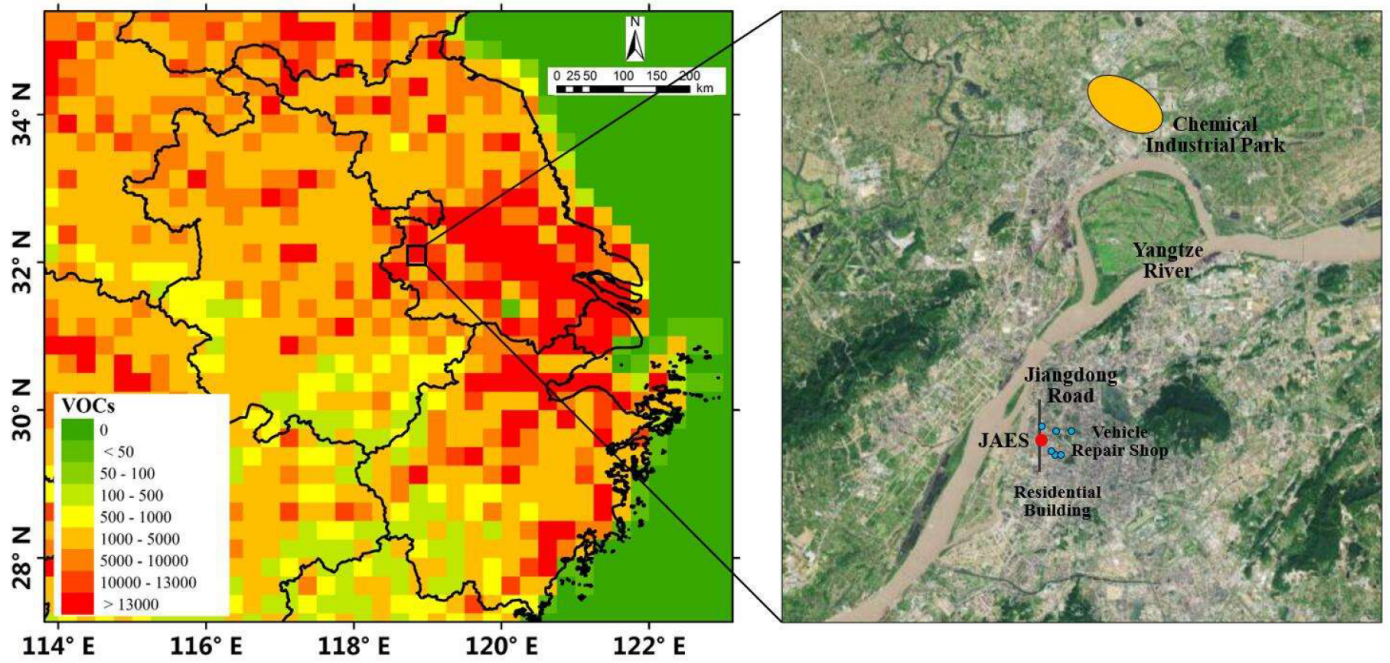

Figure 1. (a) Maps of the study location showing VOC emissions at a resolution of $0.25^{\circ}\left(\mathrm{Mg} \mathrm{a}^{-1}\right)$. (The data were taken from the MEIC emission inventory; http://www.meicmodel.org, last access: 15 September 2019.) (b) The location of the JAES sampling site is indicated by a red circle (the base map is from (C) Baidu Maps). The blue circles indicate vehicle repair shops, the yellow circle indicates chemical industry parks and the black solid line indicates a heavy-traffic road.

a PerkinElmer online ozone precursor analyzer based on a thermal desorption GC (gas chromatography) system. First, the dried air samples were collected by a thermal desorption instrument and subsequently preconcentrated onto a cold trap. The sampling flow was $15 \mathrm{~mL} \mathrm{~min}{ }^{-1}$. After $600 \mathrm{~mL}$ of air was sampled, the cold trap was heated to desorb the compounds adsorbed on to it. By applying the Dean's Switch technology, whereby the effluent is transferred from one column to another column with a different stationary phase, the low- and high-volatility components were injected into the $\mathrm{Al}_{2} \mathrm{O}_{3} / \mathrm{Na}_{2} \mathrm{SO}_{4}$ PLOT column $(50 \mathrm{~m} \times 0.22 \mathrm{~mm} \times 1 \mu \mathrm{m})$ and the dimethyl siloxane column $(50 \mathrm{~m} \times 0.32 \mathrm{~mm} \times 1 \mu \mathrm{m})$, respectively, and analyzed using a flame ionization detector (FID). The temperature increased from $46^{\circ} \mathrm{C}$ for $15 \mathrm{~min}$ to $170^{\circ} \mathrm{C}$ at a rate of $5^{\circ} \mathrm{C} \mathrm{min}^{-1}$ and then to $200^{\circ} \mathrm{C}$ at a rate of $15^{\circ} \mathrm{C} \mathrm{min}^{-1}$. The samples were finally held at $200^{\circ} \mathrm{C}$ for 6 $\min$.

A calibration was performed daily for quality control. The calibration curves showed good linearity with a correlation coefficient of 0.99. Seven analyses were performed repeatedly to test the precision of the 56 species. Calibrant concentrations in the gas standard mixture $\left(56 \mathrm{C}_{2}-\mathrm{C}_{12}\right.$ NMHCs (non-methane hydrocarbons), Linde Spectra Environment Gases, Inc, USA) ranged from 20 to $49 \mathrm{ppb}$ of C. The relative standard deviations of most of the 56 species were $<5 \%$, representing an error of $<0.5 \mathrm{ppb}$.

On the other hand, trace gases including $\mathrm{CO}$, $\mathrm{NO}-\mathrm{NO}_{2}-\mathrm{NO}_{x}, \mathrm{SO}_{2}$ and $\mathrm{O}_{3}$ were measured at $1 \mathrm{~min}$ resolution using the commercial instruments of TEI 48i, 42i, 43i and 49i (Thermo Electron Corporation). All these instruments were zero checked daily, span calibrated weekly and multi-point calibrated monthly. Furthermore, meteoro- logical conditions, including temperature, relative humidity, pressure, and wind speed and direction were monitored at 1 min resolution by a weather station (Vantage Pro ${ }^{\mathrm{TM}}$ and Vantage Pro 2 plus ${ }^{\mathrm{TM}}$ weather stations, Davis Instruments).

\subsection{The PMF model for VOC source identification}

In this study, the US EPA PMF (version 4.1) model, which has been widely used to conduct source apportionment of VOCs (Zhang et al., 2013; Mo et al., 2017; He et al., 2019, and references therein) was applied to the observed VOC data to identify potential VOC sources. A detailed description of the PMF model is provided by Yuan et al. (2009) and Ling et al. (2011). In brief, the PMF model is a receptor model that can identify the sources and contributions of given species without prior input of their source profiles. In this study, a total of 25 species were selected as the input for the PMF model including species with high abundances as well as typical tracers of emission sources. Species with high percentages of missing values $(>25 \%)$ were excluded (i.e., 1,3-butadiene, cis/trans2-pentene, dimethylpentane and trimethylpentane). The total concentration of the 25 selected species accounted for $\sim 92 \%$ of the total measured VOC composition. Furthermore, we calculated the total reactivity of the selected 25 species to be $\sim 90 \%$ of the total measured VOCs through the analysis of maximum incremental reactivity (MIR) (Shao et al., 2009a). The high abundance and total reactivity contributions suggest that the 25 selected species were appropriate for the PMF model simulation.

The PMF model was tested using a variety of factor numbers, and the optimum source profiles and contributions 
were determined based on the correlation between modeled and observed data, the comparison of modeled profiles with the results from emission-based measurements, and previous studies involving PMF or other receptor model simulations (i.e., HKEPD, 2015; Wang et al., 2014; An et al., 2014; Liu et al., 2008a). For example, different solutions with different factor numbers were explored, and the source apportionment results from a five-factor solution that could sufficiently explain the observed levels of VOCs were selected (details in Sect. 3.3). Compared with the five-factor solution, the four-factor solution derived two profiles that were attributable to gasoline and diesel vehicular exhaust, while most of the aromatic species in these sources and certain amounts of $\mathrm{C}_{3}-\mathrm{C}_{4}$ species from fuel evaporation were categorized under industrial emission. On the other hand, the sixfactor solution was split into a factor with a high abundance of ethyne and certain amounts of ethane $(30 \%$ in species total), $\mathrm{C}_{3}$ species and benzene ( $\sim 20 \%$ in species total), while some alkenes (18\%-80\% in species total) were incorporated into fuel evaporation. Furthermore, the performance of the five-factor solution was evaluated using various checks and sensitivity tests. Suitable correlations between the observed concentrations and those of each species predicted by the model were observed, with the correlation coefficients $\left(R^{2}\right)$ ranging from 0.60 to 0.91 , indicating that the solution adequately reproduced the observed variations of each species. All the scale residuals were within $\pm 3 \sigma$ with normal distributions for all species (Baudic et al., 2016). Moreover, different numbers of start seeds were tested during the simulation and no multiple solutions were found. The obtained ratio of $Q$ (robust) $/ Q$ (true) was $\sim 0.93$, close to 1 as suggested by previous studies and the user guide manual (Paatero, 2000; Lau et al., 2010; Ling et al., 2016). In addition, the results from bootstrapping analysis for the five-factor solution with bootstrap random seed found that all the factors were mapped to a basic factor in all 20 bootstrap runs, while the uncertainties of each species from bootstrapping analysis were within the range of $1 \%-20 \%$. In this study, different $F_{\text {peak }}$ values ranging from -5 to 5 were tested in the five-factor solution for a more realistic profile (Lau et al., 2010; Baudic et al., 2016). The profiles with the nonzero $F_{\text {peak }}$ values were consistent with those with zero $F_{\text {peak }}$ value, reflecting that there was little rotation for the selected solution, confirming that the profiles were reasonably explained by the five-factor solution (Baudic et al., 2016). The results of the $F_{\text {peak }}$ value equals 0.5 run (the base run) was selected for analysis in this study. Overall, the above features demonstrated that the fivefactor solution from PMF could provide reasonable and stable apportionment results for the observed VOCs at the JAES site.

\section{Results and discussion}

\subsection{VOC observation statistics}

Table 1 shows the average concentration and standard deviation of 56 VOC species concentrations measured at the JAES site, while Fig. S1 in the Supplement presents the time series of all pollution data collected at the JAES site. The annualaverage total VOC (TVOC, sum of the measured VOCs) concentration in 2016 was $25.7 \pm 19.1$ ppbv, with highest contributions from alkanes (13.6 $\pm 10.5 \mathrm{ppbv}, \sim 53 \%)$, followed by aromatics $(4.4 \pm 4.0 \mathrm{ppbv}, \sim 17 \%)$, acetylene $(4.5 \pm 5.5 \mathrm{ppbv}$, $\sim 17 \%)$ and alkenes $(3.2 \pm 3.3 \mathrm{ppbv}, \sim 13 \%)$. Annually, the 10 most abundant species were acetylene, propane, ethane, ethylene, butane, toluene, $i$-pentane, $i$-butane, propylene and benzene, with a combined contribution of $\sim 77 \%$ of the TVOC. This observed VOC composition suggests that VOCs at the JAES site are predominantly sourced from combustion emissions (i.e., vehicular emissions). Alkenes are mainly associated with vehicular emissions and are more photochemically reactive relative to alkanes and aromatics. The alkenes were found to have higher mixing ratios during weekdays relative to the weekends $(3.5 \pm 0.2$ vs. $2.9 \pm 0.1$ ppbv for weekdays and weekend, respectively, $p<0.05$ ), further confirming the dominant contribution of vehicular emissions to VOC levels at the JAES site.

The TVOC level in this study was lower than previous measurements from an industrial site in Nanjing, in which 43.5 ppbv of TVOC was reported (An et al., 2014). However, the high TVOC levels are likely due to the proximity of the observation site ( $\sim 3 \mathrm{~km}$ northeast) to the Nanjing chemical industry area, as well as several iron, steel and cogeneration power plants (within $2 \mathrm{~km}$ ) (An et al., 2014). The variability in land use between these two studies have also resulted in distinct VOC component profiles. In the industrial area, the relative contributions of alkenes and aromatics were as high as $25 \%$ and $22 \%$, while the contribution of alkynes was only $7 \%$ (An et al., 2014). The alkane, alkene and aromatic concentrations from the industrial site were 1.4, 3.4 and 2.2 times higher than the concentrations of this study, respectively, while alkyne concentrations were $\sim 30 \%$ lower. Given the large variability observed between the two sites, it is crucial to assess the spatial variability of ambient VOCs across the city through a collaboration of multiple research groups using available real-time and online VOC-monitoring systems.

Table S1 in the Supplement compares reported ambient VOCs from continuous measurements of $\geq 1$ year in several megacities in a number of countries, including China. Continuous online measurements of ambient VOCs have only been available in China since 2010, unlike many developed countries whereby online VOC measurements have been available for multiple decades. In China, such measurements are only concentrated in a few megacities, including Beijing, Guangzhou and Shanghai. The TVOC level reported 
Table 1. The average mixing ratios and standard deviation of VOC species concentrations measured at the JAES site from January to December 2016. Values in bold font are the sum of mixing ratios of measured VOCs in each group.

\begin{tabular}{|c|c|c|c|}
\hline Species & Average \pm standard deviation (ppbv) & Species & Average \pm standard deviation (ppbv) \\
\hline Alkanes & $13.64 \pm 10.53$ & Alkenes & $3.24 \pm 3.28$ \\
\hline Ethane & $3.63 \pm 2.68$ & Ethene & $1.72 \pm 2.00$ \\
\hline Propane & $3.70 \pm 3.01$ & Propylene & $0.92 \pm 1.16$ \\
\hline$i$-Butane & $1.03 \pm 0.87$ & 1-Butene & $0.12 \pm 0.16$ \\
\hline$n$-Butane & $1.55 \pm 1.26$ & cis-2-Butene & $0.06 \pm 0.09$ \\
\hline Cyclopentane & $0.08 \pm 0.10$ & trans-2-Butene & $0.16 \pm 0.11$ \\
\hline$i$-Pentane & $1.15 \pm 1.24$ & 1-Pentene & $0.03 \pm 0.03$ \\
\hline$n$-Pentane & $0.61 \pm 0.60$ & cis-1-Pentene & $0.02 \pm 0.03$ \\
\hline 2,2-Dimethylbutane & $0.02 \pm 0.02$ & trans-2-Pentene & $0.02 \pm 0.03$ \\
\hline 2,3-Dimethylbutane & $0.05 \pm 0.07$ & Isoprene & $0.14 \pm 0.20$ \\
\hline 2-Methylpentane & $0.26 \pm 0.29$ & $n$-Hexene & $0.05 \pm 0.03$ \\
\hline 3-Methylpentane & $0.16 \pm 0.21$ & Aromatics & $4.40 \pm 4.01$ \\
\hline$n$-Hexane & $0.40 \pm 0.45$ & Benzene & $0.80 \pm 0.70$ \\
\hline Methylcyclopentane & $0.26 \pm 0.27$ & Toluene & $1.40 \pm 1.35$ \\
\hline Cyclohexane & $0.10 \pm 0.16$ & Ethylbenzene & $0.50 \pm 0.62$ \\
\hline 2,4-Dimethylpentane & $0.03 \pm 0.01$ & $m / p$-Xylene & $0.70 \pm 0.71$ \\
\hline 2,3-Dimethylpentane & $0.03 \pm 0.02$ & $o$-Xylene & $0.25 \pm 0.24$ \\
\hline 2-Methylhexane & $0.06 \pm 0.09$ & Styrene & $0.12 \pm 0.17$ \\
\hline 3-Methylhexane & $0.07 \pm 0.10$ & $n$-Propylbenzene & $0.03 \pm 0.03$ \\
\hline Heptane & $0.09 \pm 0.11$ & $i$-Propylbenzene & $0.03 \pm 0.04$ \\
\hline Methylcyclohexane & $0.07 \pm 0.09$ & $m$-Ethyltoluene & $0.11 \pm 0.14$ \\
\hline 2,2,4-Trimethylpentane & $0.02 \pm 0.03$ & $p$-Ethyltoluene & $0.05 \pm 0.07$ \\
\hline 2,3,4-Trimethylpentane & $0.02 \pm 0.01$ & $o$-Ethyltoluene & $0.04 \pm 0.05$ \\
\hline 2-Methylheptane & $0.02 \pm 0.02$ & $1,3,5$-Trimethylbenzene & $0.04 \pm 0.06$ \\
\hline 3-Methylheptane & $0.02 \pm 0.02$ & 1,2,4-Trimethylbenzene & $0.15 \pm 0.21$ \\
\hline Octane & $0.04 \pm 0.06$ & 1,2,3-Trimethylpentane & $0.10 \pm 0.14$ \\
\hline Nonane & $0.02 \pm 0.02$ & $m$-Diethylbenzene & $0.03 \pm 0.06$ \\
\hline Decane & $0.04 \pm 0.04$ & $p$-Diethylbenzene & $0.04 \pm 0.08$ \\
\hline Undecane & $0.04 \pm 0.07$ & Acetylene & $4.47 \pm 5.49$ \\
\hline Dodecane & $0.09 \pm 0.20$ & - & - \\
\hline
\end{tabular}

in Nanjing was close to levels measured in Shanghai (another megacity in the YRD, East China, 27.8 ppbv) (Wang et al., 2013), Tianjin (a megacity in North China, 28.7 ppbv) (Liu et al., 2016), and Wuhan (a megacity located in central China, 24.3 ppbv) (Lyu et al., 2016), but it was considerably lower than Beijing (North China, 35.2 ppbv) (Zhang et al., 2017) and Guangzhou (southern China, $42.7 \mathrm{ppbv}$ ) (Zou et al., 2015). Alkanes were the dominant hydrocarbon group in all the cities; however, some differences in relative contributions of the four classes were observed. The contribution from aromatics was highest in Shanghai $(31 \%)$ relative to the other cities, which is likely explained by the large petrochemical and steel industry in Shanghai (Huang et al., 2011; Wang et al., 2013). In comparison, the contribution of aromatics in Guangzhou (Zou et al., 2015) and the industrial area in Nanjing (An et al., 2014) were $24 \%$ and $22 \%$, respectively, while in other cities the contribution ranged from $17 \%$ to $19 \%$. The current ambient VOC concentrations in Chinese megacities are generally comparable to the urban VOC levels in developed countries during the year 2000. However, in developed countries, the mixing ratios of VOCs were observed to decrease in the recent decades following the implementation and formulation of VOC strategies (Warneke et al., 2012). For example, the mixing ratios of VOCs in Los Angeles have decreased significantly from 1960 to 2002 at an average annual rate of $\sim 7.5 \%$, while the mixing ratios of VOCs in London presented a higher and faster decrease since 1998 when there were higher VOC mixing ratios than those in Los Angeles, confirming that the earlier implementation of VOC reduction strategies in California had clearly led to the earlier improvement of air quality compared to London (Warneke et al., 2012; von Schneidemesser et al., 2010). Chinese megacities are therefore experiencing significantly higher ambient VOC contamination, given the remarkable decrease in VOC emissions in developed countries over the last 2 decades (Pan et al., 2015; European Environment Agency, 2016; U.S. EPA, 2017). High VOC levels in Chinese megacities are known to impact ambient ozone and secondary particle pollution and cause adverse impacts on human health. However, as China has a solid foundation for VOCs monitoring and control, nu- 
merous strict, appropriate and targeted reduction strategies for VOCs have been and are being formulated and implemented in Chinese megacities (Guo et al., 2017). It is expected these measures could help China to reduce VOC emissions and mixing ratios and improve air quality in the future.

\subsection{Temporal variability}

In this study, ambient VOCs showed significant seasonal variability, with relatively high monthly-average concentrations in winter $(40.2 \pm 24.0 \mathrm{ppbv})$ and spring (23.8 \pm $15.0 \mathrm{ppbv}$ ) and low concentrations in summer (18.5 \pm $14.6 \mathrm{ppbv})$ and autumn $(20.1 \pm 12.2 \mathrm{ppbv})$. As shown in Fig. S2, the highest monthly-average concentration was observed in December, followed by January. High pollution levels during the winter period are usually expected and explained by atmospheric temperature inversions caused by cooler weather, which inhibits particle dispersion. Lower concentrations during the summer period are due to both favorable diffusion conditions and photochemical degradation of VOCs.

High levels of wintertime VOC pollution were also reported in Shanghai (Wang et al., 2013), Guangzhou (Zou et al., 2015), and Tianjin (Liu et al., 2016), though some differences in the monthly VOC variability were also observed. Except for the winter months, similar (and relatively stable) ambient VOC levels in the remaining months were observed for Guangdong (Fig. 3). In Shanghai, relatively high levels of VOCs were observed from October to January of the following year and from June to July based on the 2-year measurements conducted from 2009 to 2010 (Wang et al., 2013). The inversion layer, the effect of cold front or uniform pressure in winter resulted in high levels of VOCs from October to January of the following year, while the frontal inverted trough or frequently observed stagnant high-pressure system with southwest flow that could lead to poor diffusion were unfavorable meteorological conditions for high VOC levels from June to July. In addition, air masses transported from upwind chemical and petrochemical industrial factories located in the southwest and south of the monitoring site were another factor for the high VOC levels in summer (i.e., June and July) and winter. VOC concentrations in Tianjin showed significant monthly variability. Highest concentrations were reported in autumn and lowest concentrations were reported in summer. The observed monthly variability is affected by several factors including the type and level of emissions and local meteorological conditions.

Figure S3 shows the diurnal trends in ambient VOCs for each month. The diurnal patterns were generally similar for all the months. The observed peak at approximately 08:0009:00 LT (local time) corresponds with the city's morning traffic rush hours. The concentration begins to decrease after 09:00 LT, with lowest concentrations observed at approximately 15:00 LT. The observed decline was likely due to reduced vehicle emissions, growth of the inversion top and en- hanced photochemical VOC degradation. After 15:00 LT, the concentrations begin to increase gradually as a result of increased vehicle emissions during the evening rush hour, as well as a reduction in the atmospheric mixing height under evening meteorological conditions. The second evening VOC peak was less prominent than the morning peak. Evening concentrations were generally higher than the daytime concentrations, and the amplitudes of diurnal variability were larger in autumn and summer compared to winter and spring.

\subsection{Source apportionment of VOCs}

In this study, we applied the PMF model to apportion the sources of VOCs at the sampling site. Figure 4 illustrates the source profiles of the VOCs produced by the PMF model. Five VOC sources were resolved by PMF, including biogenic emissions (source 1), fuel evaporation (source 2), gasoline vehicular exhaust (source 3 ), diesel vehicular exhaust (source 4) and industrial emissions (source 5).

Source 1 was identified as biogenic emissions due to the high loading of isoprene - a typical tracer of biogenic emissions (Lau et al., 2010; Yuan et al., 2012). Source 2 was represented by high proportions of 2-methylpentane, 3 -methylpentane, $i$-pentane and cyclopentane. Pentanes are mainly associated with profiles from gasoline-related emissions (Barletta et al., 2005; Tsai et al., 2006). However, the low contributions of incomplete combustion tracers in this profile suggest that the VOCs are sourced from fuel evaporation. The high abundance of pentanes in this profile is consistent with the source profile of gasoline volatilization extracted from principal component analysis and absolute principal component scores (PCA/APCs) based on the observed VOC data collected in an industrial area of Nanjing (An et al., 2014) and the source profile of gasoline evaporation from PMF at the suburban site and urban sites in Beijing and Hong Kong (Yuan et al., 2009; Lau et al., 2010). In particular, based on the emission-based measurement, Liu et al. (2008b) conducted source apportionments of VOCs in the Pearl River Delta region by the chemical mass balance (CMB) receptor model, which attributed the source with high loadings of $n / i$ pentanes, cyclopentane and 2/3-methylpentane as gasoline evaporation. Therefore, source 2 here was identified as fuel evaporation.

Sources 3 and 4 were identified as vehicular exhaust due to their high loadings of incomplete combustion tracers, i.e., $\mathrm{C}_{2}-\mathrm{C}_{4}$ alkanes and alkenes (Guo et al., 2011a, b; Zhang et al., 2018). Zhang et al. (2018) compared the VOC composition of vehicular emissions from Zhujiang Tunnel in 2014 and 2004 in the Pearl River Delta region with those from other tunnel measurements. $\mathrm{C}_{2}-\mathrm{C}_{4}$ alkanes and alkenes were found to made the greatest contributions to the loading of VOCs emitted from vehicles in 2014. The higher proportions of $n / i$-pentane, $n$-hexane and methylcyclopentane in source 3 relative to source 4 indicated that VOCs were 


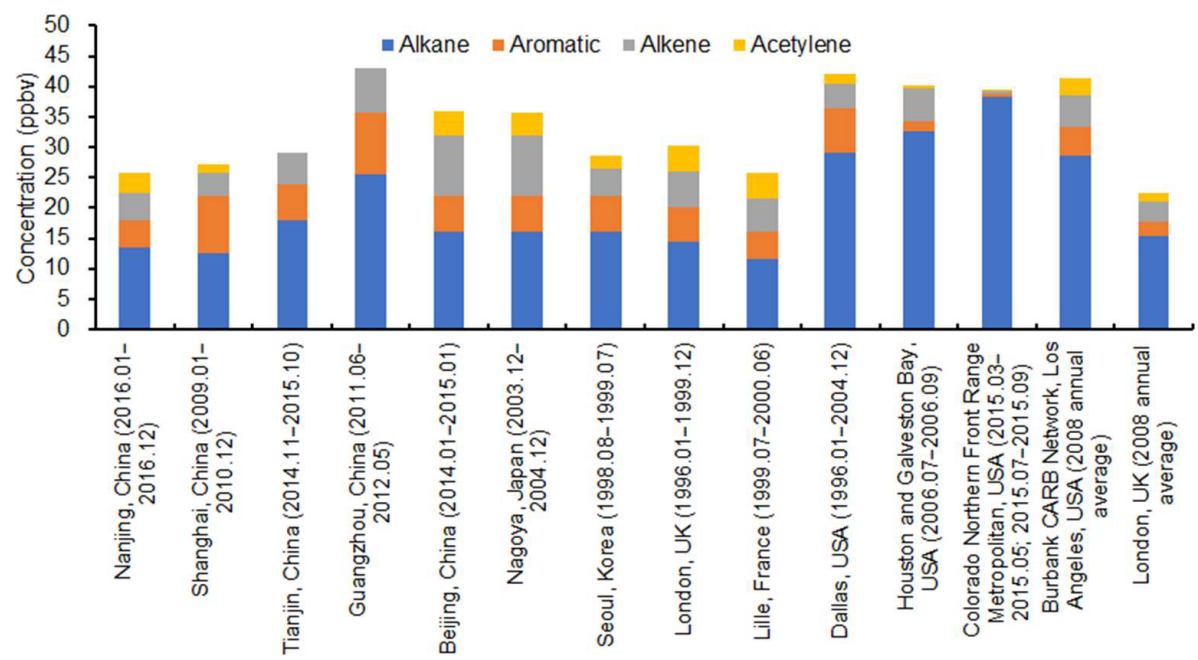

Figure 2. Comparison of annual-average concentrations of ambient VOC in different cities based on real-time online continuous measurements of at least 1 year.

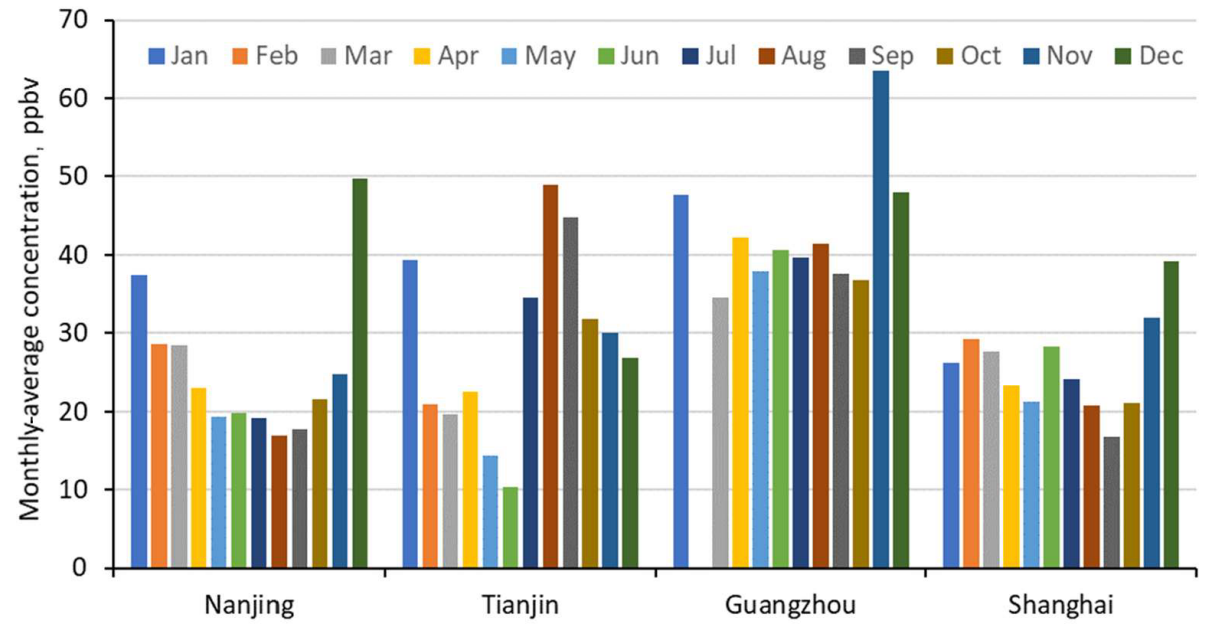

Figure 3. Monthly variability of ambient VOCs at the JAES site and three other Chinese cities: Shanghai (Wang et al., 2013), Guangzhou (Zou et al., 2015) and Tianjin (Liu et al., 2016).

sourced from gasoline vehicular exhaust (Liu et al., 2008b; Guo et al., 2011b; Zhang et al., 2018). Source 4 was identified as diesel vehicular exhaust due to the high percentages of ethyne, ethane and propene, as well as $\mathrm{C}_{2}-\mathrm{C}_{4}$ alkenes (Ho et al., 2009; Cai et al., 2010; Ou et al., 2015; Liu et al., 2008c). Source 5 was characterized by high concentrations of aromatics. In addition to gasoline vehicle emissions, industrial emission could be another important contributor to ambient aromatic hydrocarbons in the Yangtze River Delta, Pearl River Delta and North China Plain (Yuan et al., 2009; Zhang et al., 2013; An et al., 2014; Mo et al., 2015, 2017; He et al., 2019). The tunnel studies and emission-based measurement results found that aromatic hydrocarbons from gasoline vehicular exhaust were coherently emitted with pentanes, butenes, $n$-hexane and cyclopentane, which were more consistent with the profile in source 3 mentioned above (Liu et al., 2008a, b, c; Ho et al., 2009; Yuan et al., 2009; Zhang et al., 2018). Therefore, the absence of the above species in source 5 indicated that this source could be related to industrial emission (Zhang et al., 2014). In particular, the high abundances of toluene, ethylbenzene, xylenes, ethyltoluene and trimethylbenzene were consistent with the emission-based measurement results conducted in the paint and printing industries (Yuan et al., 2010) and manufacturing facilities (Zheng et al., 2013). On the other hand, the profile with a high abundance of aromatic hydrocarbons $\left(\mathrm{C}_{7}-\mathrm{C}_{9}\right.$ aromatics) and a certain amount of ethene was also in agreement with the profiles measured in the areas dominated by industrial emissions in the Yangtze River Delta region (An et al., 2014; Shao et al., 2016; Mo et al., 2017). For example, 
An et al. (2014) reported that toluene, ethylbenzene, xylenes and trimethylbenzenes could be emitted from different industrial processes, and they identified that the factors with high loadings of these species as industrial production, solvent usage and industrial production of volatilization sources by PCA/APCs at the industrial area in Nanjing. On the other hand, Mo et al. (2017) identified the factors with high concentrations of $\mathrm{C}_{7}-\mathrm{C}_{9}$ aromatics and ethene, as used in residential solvent usage and the chemical, paint, and petrochemical industries, with the PMF model applied to the data collected in an industrialized coastal city of the Yangtze River Delta. To further identify sources 3 and 5 , the ratio of toluene to benzene ( $\mathrm{T} / \mathrm{B}$, ppbv ppbv ${ }^{-1}$ ) in each profile was compared with those obtained from emission-based measurements and tunnel study results (Zhang et al., 2018, and references therein). The ratios of $\mathrm{T} / \mathrm{B}$ were $\sim 8.2$ and $\sim 1.2$ for sources 5 and 3 , respectively, and were consistent with those of "industrial processes and solvent application" and "roadside and tunnel study", respectively (Zhang et al., 2018, and references therein). This further confirmed that source 3 was related to gasoline vehicular exhaust, while source 5 was associated with industrial emission.

Vehicular exhaust was found to be the most significant contributor to the TVOCs at the JAES site, with average contributions of $\sim 34 \%$ and $\sim 27 \%$ for diesel and gasoline exhaust, respectively, followed by industrial emissions (19\%), fuel evaporation $(\sim 15 \%)$, and biogenic emissions $(\sim 4 \%)$. Our results are inconsistent with previous results observed at industrial sites in Nanjing (An et al., 2014; Xia et al., 2014a). An et al. (2014) found that industrial activities were the most significant source of VOCs, contributing $45 \%-63 \%$ (mainly aromatic VOCs), followed by vehicle emission at $34 \%-50 \%$. Similarly, Xia et al. (2014a) reported solvent usage and other industrial sources to account for most $(31 \%)$ of the VOCs in a suburban site in southwestern Nanjing, close in proximity to Nanjing's industrial zone. Fossil fuel, biomass and biofuel combustion were the second highest contributors at $28 \%$, while the average contribution of vehicular emissions was $17 \%$, mainly from the northern center of Nanjing (Xia et al., 2014a). Combined, these results infer vehicular emissions to be a major component of urban emissions in Nanjing. The observed spatial variability in the contributions of VOC sources infers the complex emissions characteristics of VOCs in Nanjing, likely due to the city's unique industrial structure. For example, the sampling site (i.e., the JAES site) was located in a more residential and urban area compared to other sites listed in An et al. (2014) and Xia et al. (2014a). There are more than 0.22 million people living in the areas surrounding the sampled site (within $3 \mathrm{~km}$ of the observation site), which is composed of residential communities, schools, government agencies and business centers. These results also demonstrate that local emissions are dominant contributors to ambient VOC levels in Nanjing.

The dominant contribution of vehicular emissions to ambient VOCs in Nanjing is consistent with the urban or central areas of other large cities, including Hong Kong, Guangzhou, Shanghai and Beijing, as identified and quantified by the PMF model (Yuan et al., 2009; Cai et al., 2010; Guo et al., 2011a; Zhang et al., 2013; Wang et al., 2015). In addition, our results are in agreement with the anthropogenic VOC source emission inventory of Jiangsu Province in 2010 (Xia et al., 2014b), indicating vehicular emissions and industrial emissions (i.e., solvent usage and industrial process source) to be the two dominant sources of VOCs in the region. However, the contributions of vehicle-related emissions (i.e., $\sim 25 \%$ ) and industrial emissions were lower and higher than those quantified by the PMF model in this study, respectively. The observed discrepancy between the two studies may be due to differences in source categories, measured VOC species, and/or sampling locations and methods used in the different models. For example, the VOC sources in Jiangsu Province were categorized into vehicular related emission $(\sim 26 \%)$, industrial solvent usage $(\sim 25 \%)$, fossil fuel combustion $(\sim 24 \%)$, industrial processes $(\sim 22 \%)$ and biomass burning $(\sim 3 \%)$. Further, vehicle-related emissions only included emissions from motor vehicles and ships and the volatilization of fuel, while solvent usage included organic solvents volatilized from a variety of industries (the industrial production of electronic equipment, furniture, printing, packaging, inks, adhesives, etc. as well as other dry cleaning, catering and architectural decoration processes). The higher vehicular emission contribution in this study may also be due to the increasing number of vehicles from 2010 to 2014 as a result of increased urbanization and industrialization (Statistical yearbook of Nanjing, 2014).

Figure 5 illustrates the mean diurnal variability of all identified sources at the JAES site. These trends were influenced by the variability in emission strength, mixing height, and the concentrations and photochemical reactivity of individual species in each source profile. For example, we observed a typical diurnal pattern with a broad peak between 09:00 and 18:00 LT (local time) for biogenic emissions, as the emission rate of isoprene from vegetation is largely depended on ambient temperature and sunlight intensity. Higher levels of diesel and gasoline vehicular emissions were observed in the evening and early morning due to a reduced mixing height and increased emissions from the morning and evening rush hours. Lower concentrations observed during daytime hours were likely due to decreased emissions, an increased mixing height and enhanced photochemical loss (Gillman et al., 2009; Yuan et al., 2009; Wang et al., 2013). A diurnal pattern of fuel evaporation was similar to that of vehicular emissions. Though the evaporation of fuel is dependent on temperature, the average temperature in the morning and evening (i.e., 08:00-10:00 and 17:00-19:00 LT, respectively) when peaks of fuel evaporation were found was only about $\sim 1.2^{\circ} \mathrm{C}$ lower than that observed from noon to afternoon (11:00-16:00 LT), which may not result in much higher fuel evaporation at noon (the difference between maximum and minimum values for fuel evaporation was found to be 


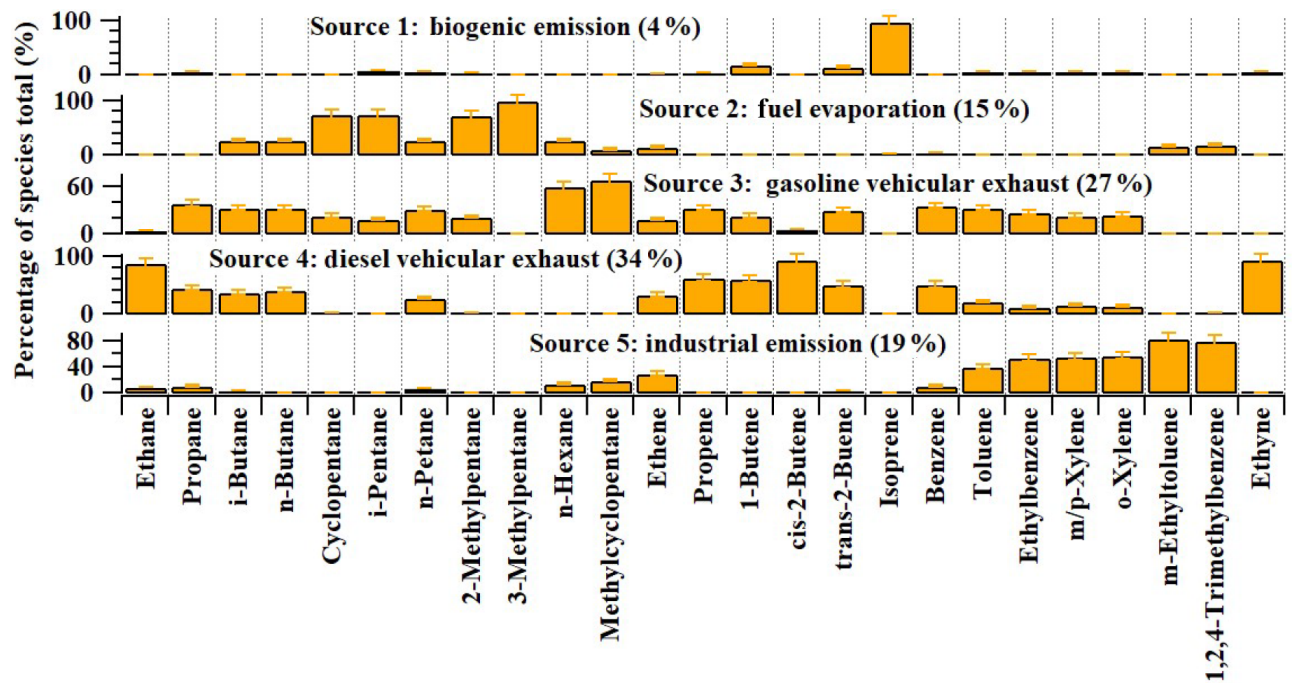

Figure 4. Source profiles of VOCs identified using the PMF model and the relative contributions of the individual VOC species.

$\sim 6 \mu \mathrm{g} \mathrm{m}^{-3}$ ). On the other hand, in addition to evaporation from the gas station, fuel could evaporate from hot engines, fuel tanks and the exhaust system when the car is running. Furthermore, the engine remains hot for a period of time after the car is turned off, and gasoline evaporation continues when the car is parked (Technology Center, University of Illinois; https://mste.illinois.edu/tcd/ecology/fuelevap.html, last access: 25 December 2019). The similarity of diurnal variations of fuel evaporation to vehicular emissions suggest that the prominent peak in the morning and evening hours are related to the increased vehicles in the traffic rush hours and emissions accumulated in the relatively low boundary layer. Moreover, we identified higher concentrations of industrial emissions at night and in the early morning, with values remaining fairly stable during daytime hours. This finding is consistent with other observations in urban and rural areas (Yuan et al., 2009; Leuchner and Rappenglück, 2010).

\subsection{Contributions of VOC sources to $\mathrm{O}_{3}$ formation}

As important $\mathrm{O}_{3}$ precursors, information on the contributions of VOC sources and related species to $\mathrm{O}_{3}$ formation is necessary for the formulation and implementation of VOC control measures. To achieve this goal, the maximum incremental reactivity (MIR) method, which evaluates the $\mathrm{O}_{3}$ formation potential (OFP) on the basis of mass concentrations and maximum incremental reactivities of VOCs with the $\mathrm{OH}$ radical, was adopted in the present study (Shao et al., 2009b, 2011; Mo et al., 2017). Figure 6 presents the relative contributions of individual VOC sources and related VOC species from PMF to OFP at the JAES site. Industrial emissions were found to have the largest OFP at JAES due to the high loadings of aromatic VOC species that have relatively high $\mathrm{OH}$ reactivities in this source profile (Atkinson and Arey, 2003), with the OFP value of $\sim 43 \mu \mathrm{g} \mathrm{m}^{-3}$ and the contri- bution percentage of $\sim 32 \%$ to the total OFP of all VOC sources, followed by diesel vehicular exhaust $\left(\sim 36 \mu \mathrm{g} \mathrm{m}^{-3}\right.$, $\sim 27 \%)$, gasoline vehicular exhaust $\left(\sim 32 \mu \mathrm{g} \mathrm{m}^{-3}, \sim 24 \%\right)$ and fuel evaporation $\left(\sim 13 \mu \mathrm{g} \mathrm{m}^{-3}, \sim 10 \%\right)$. Furthermore, though the MIR value of isoprene was much higher than other VOC species, biogenic emissions only contributed $\sim$ $7 \%\left(\sim 9 \mu \mathrm{g} \mathrm{m}^{-3}\right)$ to the total OFP of all VOC sources as the relatively low mixing ratio of isoprene at the JAES site. Similarly, using the same method to evaluate OFP of different VOC sources, Mo et al. (2017) found that industrial emissions (including the emissions of the petrochemical industry, chemical and paint industries, solvent usage) and vehicular emissions were the dominant VOC sources of the total OFP in an industrialized coastal city (i.e., Ningbo) in the YRD region. Therefore, our results further demonstrate the need to minimize VOC emissions from industrial emissions and vehicle exhaust in order to lower $\mathrm{O}_{3}$ formation and photochemical pollution in the YRD.

Based on the mass concentrations of individual species in each source, we found that $m, p$-xylene and toluene in industrial emissions and gasoline vehicular emissions; propene, ethene, toluene, and $m, p$-xylene in diesel vehicular emissions; and $o$-xylene, 1,2,4-trimethylbenzene, and ethene in industrial emissions to be the dominant species from VOC emissions contributing to photochemical $\mathrm{O}_{3}$ formation. Thus, only a small number of VOC species can be monitored for the effective control of $\mathrm{O}_{3}$ formation.

\subsection{Policy summary and implications}

To effectively control photochemical pollution, the Prevention and Control of Atmospheric Pollution Act was passed in 1987 and amended in 2015. As a result, a series of measures to prevent and control VOC levels have been and are being implemented by central and local governments, includ- 

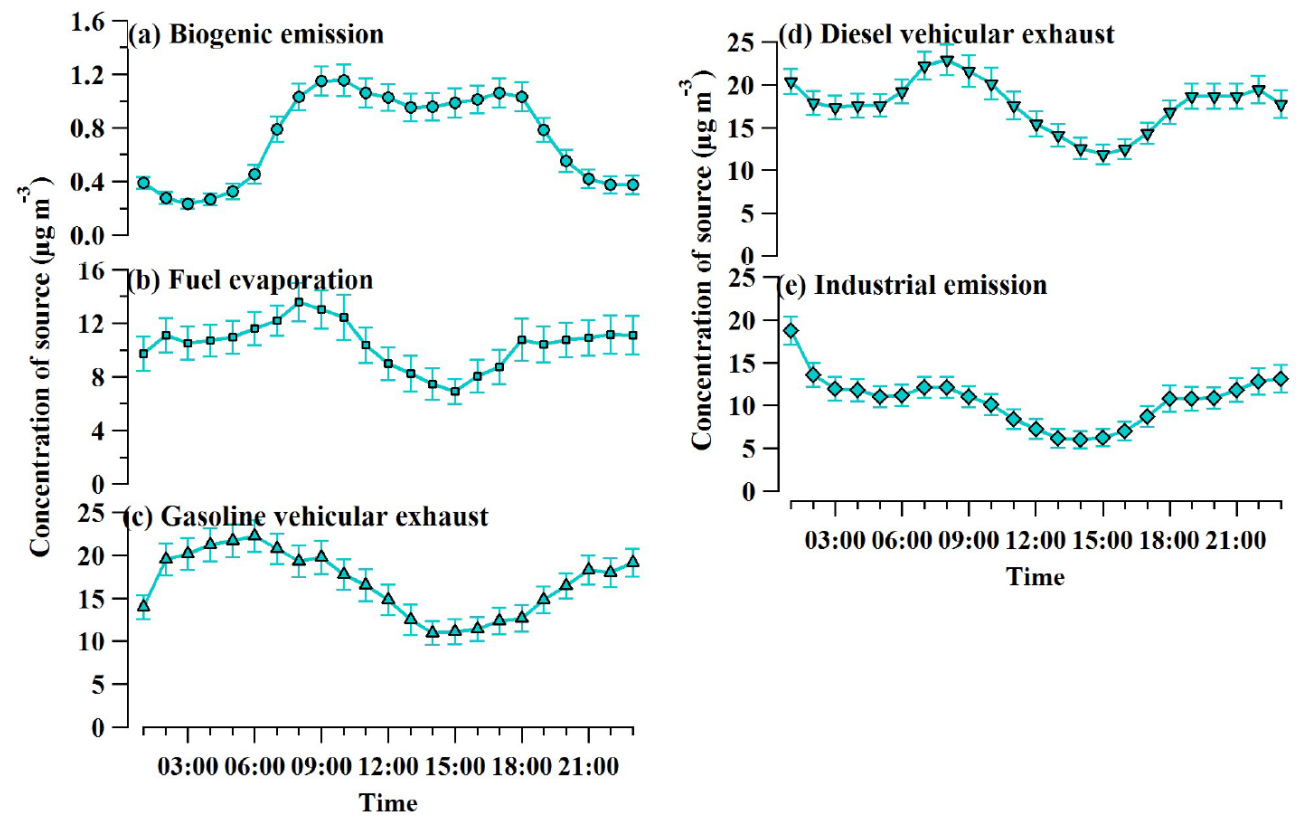

Figure 5. Diurnal patterns in source concentrations of the five identified sources.

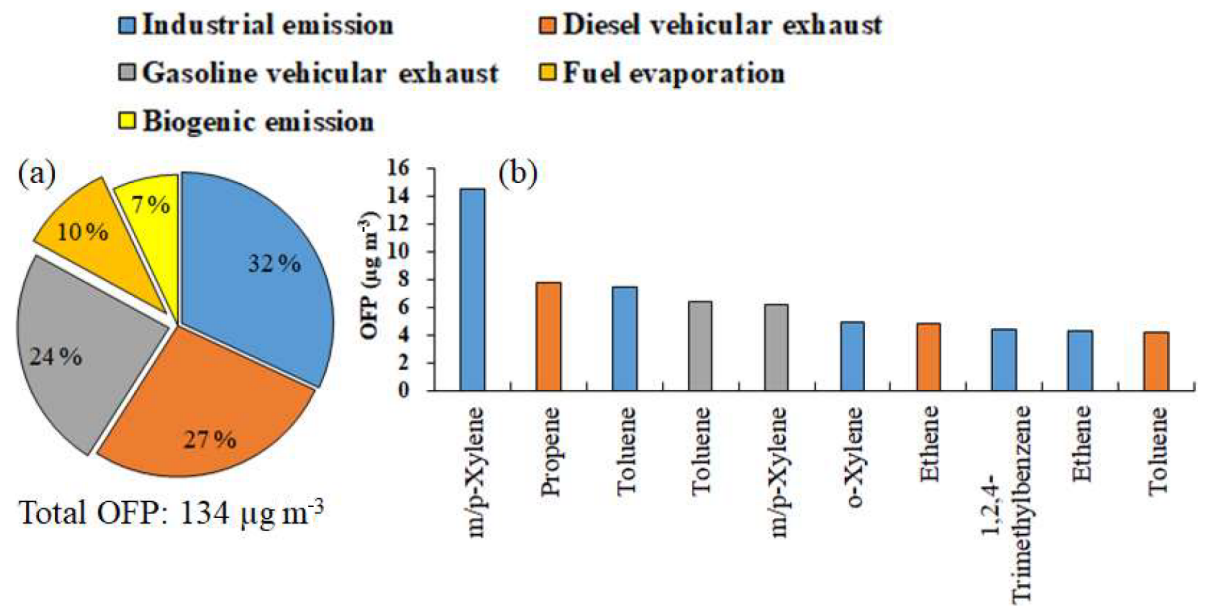

Figure 6. (a) The contribution of individual sources to the total OFP of all sources extracted from PMF and (b) OFP values of the top 10 VOC species in the different source categories.

ing the implementation of new laws and regulations and the advancement of technology. The results of this study suggest that photochemical $\mathrm{O}_{3}$ formation within the urban areas of Nanjing city are VOC limited, which is consistent with observations in the urban locations of other regions, including the North China Plain, the Yangtze River Delta and the Pearl River Delta. Minimizing VOC emissions and their concentrations should therefore be prioritized in order to alleviate $\mathrm{O}_{3}$ pollution in urban environments. The prevention and control of VOC pollution has been listed as one of the key tasks of the "Blue Sky" project initiated in 2012 by the Department of Environmental Protection of Jiangsu Province. Furthermore, the administrative measures on the Prevention and
Control of Volatile Organic Compounds Pollution in Jiangsu (Order No. 119 of the Provincial Government) was enacted on 6 March 2018 and implemented on 1 May 2018, with the aim of controlling VOC emissions in Jiangsu Province.

In order to achieve these goals, various measures have been implemented (Table S2), including (1) investigating the current pollution status and identifying the progress of VOC prevention and control in Jiangsu Province (Provincial Office of the Joint Conference on the prevention and control of air pollution [2012] No. 2); (2) conducting a strict industry access system, under the Advice on Promoting Air Pollution Joint Prevention and Control Work to Improve Regional Air Quality (Office of the State Council [2010] No. 
33); (3) strengthening the remediation on existing sources of VOCs and reducing VOC emissions from these sources, under the guidelines for the implementation of Leak Detection and Repair (LDAR) in Jiangsu Province (Trial) (Provincial Office of Environmental Protection [2013] No. 318); (4) strengthening the VOC monitoring capacity, under the Guidelines for Control of Volatile Organic Compounds Pollution in Key Industries in Jiangsu Province (Provincial Office of Environmental Protection [2013] No. 128); (5) improving standards regarding VOC emissions for key industries, including standards for surface coating of the automobile manufacturing industry (DB32/2862-2016), the chemical industry (DB32/3151-2016) and furniture manufacturing operations (DB32/3152-2016), which are still effective since their enforcement; (6) implementing the Pilot Measures for Volatile Organic Compounds Discharge Charges (Ministry of Finance [2015] No. 71) on 1 October 2015 to raise awareness pertaining to emissions reduction in factories and to control VOC emissions from industrial sources; (7) encouraging the public to live a low-carbon life and supervise and offer recommendations in accordance with the laws, under the Measures for Public Participation in Environmental Protection in Jiangsu Province (Trial) (Provincial Regulation of Environmental Protection Office [2016] No. 1).

Based on the VOC source apportionment results in this study, we identified vehicular emissions and industrial emissions as the two major VOC sources contributing to photochemical $\mathrm{O}_{3}$ formation. Other measures and/or regulations have been conducted in Jiangsu Province to effectively control VOC emissions from vehicles and industry. For vehicular emissions, the Regulations on Prevention and Control of Vehicle Exhaust Pollution in Nanjing was amended in July 2017 and subsequently in March 2018 (http://www. jiangsu.gov.cn/art/2019/4/30/art_59202_8323581.html, last access: 28 March 2020). The new regulation not only focuses on vehicle emissions but also incorporates a number of additional topics, including optimizing the function and distribution of urban areas, limiting the number of vehicles in the region, promoting new green energy vehicles, and improving the quality of fuel. The promotion of intelligent traffic management, implementation of a priority strategy for public transportation and construction of more efficient traffic systems to promote pedestrian and bicycle use is recommended. Further studies should be conducted to estimate and manage the increasing quantity of vehicles on the road. As of 1 January 2017, regulation stipulate that all new and used vehicles should meet the fifth phase of vehicle emission standards, including vehicle manufacture, sales, registration and importation. For vehicles already in use, an environmental protection examination should be conducted annually, based on the standards of GB 14622-2016, GB 18176-2016, GB 197552016 and HJ 689-2014. Penalties are issued if qualified vehicles excessively emit pollutants due to poor maintenance.

For industrial emissions, various policies have been implemented to reduce VOC emissions, particularly in chemi- cal industries, including (1) investigations on the VOC emissions of the chemical industry and the establishment of an archive system for VOC pollution control, particularly the inspection of industry information, products and materials, and unorganized emission of storage and exhaust gas treatment facilities, under the Plan for Investigation of Volatile Organic Pollutant Emissions in Jiangsu Province, mentioned in the Provincial Office of Environmental Protection [2012] No. 183; (2) exhaust gas remediation in the chemical industry park, under the Technical Specifications for Prevention and Control of Air Pollution in Chemical Industries in Jiangsu Province (Provincial Office of Environmental Protection [2014] No. 3), which requires the establishment of the long-term supervision of exhaust gas remediation in the chemical industry park of Jiangsu Province; (3) a pilot project on the leak detection and repair (LDAR) technology in the chemical industry park, was conducted according to the documents from Provincial Office of Environmental Protection (No. 157 in 2015). The TVOC removal efficiency of organic exhaust vents should be $>95 \%$ and higher for areas of excessive environmental pollution at $>97 \%$ (GB 315712015).

Furthermore, though measures have been adopted to improve standards and control vehicle VOC emissions, most of these policies only focus on total VOC emissions (or the mass of total emissions) and do not consider the impacts of individual VOC species. To accelerate the implementation of existing policies and to strengthen collaborative regional prevention and control, priority should be placed on specific high-impact VOC species (i.e., $m, p$-xylene and toluene in the industrial emission and gasoline vehicular emission) by considering both their reactivity and abundance.

Last but not least, $\mathrm{O}_{3}$ pollution is a regional crossboundary environmental issue rather than a local pollution problem. Apart from VOCs, $\mathrm{NO}_{x}$ is another important precursor for $\mathrm{O}_{3}$ formation with its dual roles in $\mathrm{O}_{3}$ production (enhancing $\mathrm{O}_{3}$ formation in non- $\mathrm{NO}_{x}$-saturated environment and titrating $\mathrm{O}_{3}$ in $\mathrm{NO}_{x}$-saturated environment). In other areas (i.e., the rural environment and/or the downwind areas of the urban center in the same region) where the concentrations of $\mathrm{NO}_{x}$ are low and/or there is a non- $\mathrm{NO}_{x}$-saturated environment, the situation may be different and controlling VOCs should be conducted cautiously (Zheng et al., 2010; Yuan et al., 2013; Ou et al., 2016). Therefore, from a regional perspective, the benefits of VOC control measures could be further evaluated with those of $\mathrm{NO}_{x}$ (i.e., the appropriate ratios of $\mathrm{VOC} / \mathrm{NO}_{x}$ for the reduction of $\mathrm{O}_{3}$ pollution) as well as the associated $\mathrm{O}_{3}-\mathrm{VOCs}-\mathrm{NO}_{x}$ sensitivity. Therefore, one important concern for the policy formulation and implementation system is whether controlling VOCs and $\mathrm{NO}_{x}$ individually or controlling both VOCs and $\mathrm{NO}_{x}$ is more effective and appropriate for alleviating $\mathrm{O}_{3}$ pollution. It is necessary to consider the reduction ratios of $\mathrm{VOC} / \mathrm{NO}_{x}$ when VOCs and $\mathrm{NO}_{x}$ are simultaneously controlled. Finally, long-term mon- 
itoring studies are necessary to determine the costs, benefits and performance of each policy.

\section{Conclusions}

In this study, a 1-year field sampling campaign was conducted to investigate the VOC characteristics at an urban site in Nanjing (the JAES site), Jiangsu Province. In total, 56 VOCs including 29 alkanes, 10 alkenes, 16 aromatics and acetylene were identified and quantified. The composition analysis found that alkanes were the dominant group of VOCs observed at the JAES site $(\sim 53 \%)$, followed by aromatics, acetylene and alkenes. This finding is consistent with the VOC measurements in studies conducted in the North China Plain, Pearl River Delta and Yangtze River Delta. We observed distinct seasonal patterns of TVOCs, with maximum values in winter and minimum values in summer. Similarly, prominent morning and evening peaks were observed in the diurnal variability of TVOCs, influenced by local emissions and meteorology.

Based on the observed VOC data, we identified five dominant VOC sources at the JAES site using a PMF model. By considering both the abundance and maximum incremental reactivity of individual VOC species in each source, the OFP values identified industrial and vehicular emissions, particularly $m, p$-xylene, toluene and propene, as the main contributors of $\mathrm{O}_{3}$ pollution. Local governments have strengthened several measures to minimize VOC pollution from vehicle and industrial emissions in Jiangsu Province in recent years, though most of these policies focus particularly on lowering the total emissions of VOCs. Furthermore, from a regional perspective, it is suggested that appropriate ratios of VOC $/ \mathrm{NO}_{x}$, their associated sensitivity to $\mathrm{O}_{3}$ formation, and relative benefits and disadvantages of reducing $\mathrm{VOCs} / \mathrm{NO}_{x}$ should be investigated and evaluated when control measures of VOCs and $\mathrm{NO}_{x}$ are conducted.

Data availability. The research data belongs to Jiangsu Academy of Environmental Sciences, which can be accessed by application. Detailed application procedures can be obtained by request to QY Zhao (qiuyue.zhao@ 163.com) of Jiangsu Academy of Environmental Sciences.

Supplement. The supplement related to this article is available online at: https://doi.org/10.5194/acp-20-3905-2020-supplement.

Author contributions. JB, ZL and QZ designed the research and carried it out. ZL performed the data simulation. QZ and GS performed the observation data analysis. QZ prepared the article with contributions from all co-authors.
Competing interests. The authors declare that they have no conflict of interest.

Acknowledgements. The authors thank Hai Guo of Hong Kong Polytechnic University for the suggestion of model simulation, and they also thank the handling editor and two anonymous referees for their constructive comments for the article.

Financial support. This work was supported by the National Key R\&D Program of China (nos. 2016YFC0207607, 2017YFC0210106), the National Science Foundation of Jiangsu Province of China (General Program, no. BK20161601), the Open Research Fund of Jiangsu Province Key Laboratory of Environmental Engineering (no. ZX2016002) and the National Natural Science Foundation of China (no. 41775114). This work was also partly supported by the Pearl River Science and Technology Nova Program of Guangzhou (grant no. 201806010146).

Review statement. This paper was edited by Thomas Karl and reviewed by two anonymous referees.

\section{References}

An, J., Zhu, B., Wang, H., Li, Y., Lin, X., and Yang, H.: Characteristics and source apportionment of VOCs measured in an industrial area of Nanjing, Yangtze River Delta, China, Atmos. Environ., 97, 206-214, 2014.

An, J., Zou, J., Wang, J., Lin, X., and Zhu, B.: Differences in ozone photochemical characteristics between the megacity Nanjing and its suburban surroundings, Yangtze River Delta, China, Environmental Science and Pollution Research International, 22, 1960719617, 2015.

Atkinson, R. and Arey, J.: Atmospheric degradation of volatile organic compounds, Chem. Rev., 103, 4605-4658, 2003.

Barletta, B., Meinardi, S., Rowland, F. S., Chan, C. Y., Wang, X. M., Zou, S. C., Chan, L. Y., and Blake, D. R.: Volatile organic compounds in 43 Chinese cities, Atmos. Environ., 39, 5979-5990, 2005.

Baudic, A., Gros, V., Sauvage, S., Locoge, N., Sanchez, O., SardaEstève, R., Kalogridis, C., Petit, J.-E., Bonnaire, N., Baisnée, D., Favez, O., Albinet, A., Sciare, J., and Bonsang, B.: Seasonal variability and source apportionment of volatile organic compounds (VOCs) in the Paris megacity (France), Atmos. Chem. Phys., 16, 11961-11989, https://doi.org/10.5194/acp-16-119612016, 2016.

Cai, C. J., Geng, F. H., Tie, X. X., and An, J. L.: Characteristic and source apportionment of VOCs measured in Shanghai, China, Atmos. Environ., 44, 5005-5014, 2010.

Ding, A. J., Nie, W., Huang, X., Chi, X. G., Xu, Z., Thouret, V., Nedelec, P., Zheng, L. F., Xu, Z. N., Xie, Y. N., Shen, Y. C., Qi, X. M., Wang, J. P., Ding, K., Sun, J. N., Petaja, T., Kerminen, V.-M., Kulmala, M., and Fu, C. B.: Ozone in the western Yangtze River Delta of China: a synthesis study based on ground, aircraft and sounding measurement 2011-2015, 18-20 May 2016, Beijing, China The 6th PEEX meeting, 2016. 
European Environment Agency, Air quality in Europe-2016 report, No. 28/2016, available at: http://europa.eu (last access: 3 January 2020), 2016.

Fu, L., Wan, W., Zhang, W., and Cheng, H.: Air pollution prevention and control progress in Chinese cities, Clean Air Asia, China, available at: http://cleanairasia.org/wp-content/uploads/2016/08/ China-Air-2016-Report-Full.pdf, (last access: 16 May 2018), 2016

Gardiner, M. S. and Lange, C. R.: Comparison of laboratory generated and field-obtained HMA VOCs with odour potential, Int. J. Pavement Eng., 6, 257-263, 2005.

Gilman, J. B., Kuster, W. C., Goldan, P. D., Herndon, S. C., Zahniser, M. S., Tucker, S. C., Brewer, W. A., Lerner, B. M., Williams, E. J., Harley, R. A., Fehsenfeld, F. C., Warneke, C., and de Gouw, J. A.: Measurements of volatile organic compounds during the 2006 TexAQS/GoMACCS campaign: industrial influences, regional characteristics, and diurnal of dependencies of the OH reactivity, J. Geophys. Res., 114, D00F06, https://doi.org/10.1029/2008JD011525, 2009.

Guo, H., Cheng, H. R., Ling, Z. H., Louie, P. K. K., and Ayoko, G. A.: Which emission sources are responsible for the volatile organic compounds in the atmosphere of Pearl River Delta?, J. Hazard. Mater., 188, 116-124, 2011a.

Guo, H., Zou, S. C., Tsai, W. Y., Chan, L. Y., and Blake, D. R.: Emission characteristics of non-methane hydrocarbons from private cars and taxis at different driving speeds in Hong Kong, Atmos. Environ., 45, 2711-2721, $2011 \mathrm{~b}$.

Guo, H., Ling, Z. H., Cheng, H. R., Simpson, I. J., Lyu, X. P., Wang, X. M., Shao, M., Lu, H. X., Ayoko, G., Zhang, Y. L., Saunders, S. M., Lam, S. H. M., Wang, J. L., and Blake, D. R.: Tropospheric Volatile organic compounds in China, Sci. Total Envion., 574, 1021-1043, 2017.

He, Z., Wang, X., Ling, Z., Zhao, J., Guo, H., Shao, M., and Wang, Z.: Contributions of different anthropogenic volatile organic compound sources to ozone formation at a receptor site in the Pearl River Delta region and its policy implications, Atmos. Chem. Phys., 19, 8801-8816, https://doi.org/10.5194/acp19-8801-2019, 2019.

HKEPD (Hong Kong Environmental Protection Department): Characterisation of VOC sources and integrated photochemical ozone analysis in Hong Kong and the Pearl River Delta region, Final report, Hong Kong, 2015.

Ho, K. F., Lee, S. C., Ho, W. K., Blake, D. R., Cheng, Y., Li, Y. S., Ho, S. S. H., Fung, K., Louie, P. K. K., and Park, D.: Vehicular emission of volatile organic compounds (VOCs) from a tunnel study in Hong Kong, Atmos. Chem. Phys., 9, 7491-7504, https://doi.org/10.5194/acp-9-7491-2009, 2009.

Huang, C., Chen, C. H., Li, L., Cheng, Z., Wang, H. L., Huang, H. Y., Streets, D. G., Wang, Y. J., Zhang, G. F., and Chen, Y. R.: Emission inventory of anthropogenic air pollutants and VOC species in the Yangtze River Delta region, China, Atmos. Chem. Phys., 11, 4105-4120, https://doi.org/10.5194/acp11-4105-2011, 2011.

Jenkin, M. E. and Clemitshaw, K. C.: Ozone and other secondary photochemical pollutants: chemical processes governing their formation in the planetary boundary layer, Atmos. Environ., 34, 2499-2527, 2000.

Kurokawa, J., Ohara, T., Morikawa, T., Hanayama, S., JanssensMaenhout, G., Fukui, T., Kawashima, K., and Akimoto, H.:
Emissions of air pollutants and greenhouse gases over Asian regions during 2000-2008: Regional Emission inventory in ASia (REAS) version 2, Atmos. Chem. Phys., 13, 11019-11058, https://doi.org/10.5194/acp-13-11019-2013, 2013.

Lau, A. K. H., Yuan, Z., Yu, J. Z., and Louie, P. K.: Source apportionment of ambient volatile organic compounds in Hong Kong, Sci. Total Environ., 408, 4138-4149, 2010.

Leuchner, M. and Rappenglück, B.: VOC source-receptor relationships in Houston during TexAQS-II, Atmos. Environ., 44, 40564067, 2010.

Liu, B., Liang, D., Yang, J., Dai, Q., Bi, X., and Feng, Y., Yuan, J., Xiao, Z. M., Zhang, Y. F., and Xu, H.: Characterization and source apportionment of volatile organic compounds based on 1-year of observational data in Tianjin, China, Environ. Pollut., 218, 757-769, 2016.

Lyu, X., Chen, N., Guo, H., Zhang, W., Wang, N., Wang, Y., and Liu, M.: Ambient volatile organic compounds and their effect on ozone production in Wuhan, central China, Sci. Total Environ., 548-549, 483-483, 2016.

Ling, Z. H., Guo, H., Cheng, H. R., and Yu, Y. F.: Sources of ambient volatile organic compounds and their contributions to photochemical ozone formation at a site in the Pearl River Delta, southern China, Environ. Pollut., 159, 2310-2319, 2011.

Ling, Z., Guo, H., Simpson, I. J., Saunders, S. M., Lam, S. H. M., Lyu, X., and Blake, D. R.: New insight into the spatiotemporal variability and source apportionments of $\mathrm{C}_{1}-\mathrm{C}_{4}$ alkyl nitrates in Hong Kong, Atmos. Chem. Phys., 16, 8141-8156, https://doi.org/10.5194/acp-16-8141-2016, 2016.

Liu, B., Liang, D., Yang, J., Dai, Q., Bi, X., and Feng, Y., Yuan, J., Xiao, Z. M., Zhang, Y. F., and Xu, H.: Characterization and source apportionment of volatile organic compounds based on 1-year of observational data in Tianjin, China, Environ. Pollut., 218, 757-769, 2016.

Liu, Y., Shao, M., Fu, L. L., Lu, S. H., Zeng, L. M., and Tang, D. G.: Source profiles of volatile organic compounds (VOCs) measured in China: Part I, Atmos. Environ. 42, 6247-6260, 2008a.

Liu, Y., Shao, M., Lu, S., Chang, C. C., Wang, J. L., and Fu, L.: Source apportionment of ambient volatile organic compounds in the Pearl River delta, China: part II, Atmos. Environ., 42, 62616274, 2008b.

Liu, Y., Shao, M., Lu, S., Chang, C.-C., Wang, J.-L., and Chen, G.: Volatile Organic Compound (VOC) measurements in the Pearl River Delta (PRD) region, China, Atmos. Chem. Phys., 8, 15311545, https://doi.org/10.5194/acp-8-1531-2008, 2008c.

Mo, Z., Shao, M., Lu, S., Qu, H., Zhou, M., and Gou, B.: Processspecific emission characteristics of volatile organic compounds (VOCs) from petrochemical facilities in the Yangtze River Delta, China, Sci. Total Environ., 533, 422-431, 2015.

Mo, Z., Shao, M., and Lu, S.: Compilation of a source profile database for hydrocarbon and OVOC emissions in China, Atmos. Environ., 143, 209-217, 2016.

Mo, Z., Shao, M., Lu, S. H., Niu, H., Zhou, M. Y., and Sun, J.: Characterization of non-methane hydrocarbons and their sources in an industrialized coastal city, Yangtze River Delta, China, Sci. Total Environ., 593-594, 641-653, 2017.

Ou, J., Guo, H., Zheng, J., Cheung, K., Louie, P. K. K., Ling, Z., and Wang D. W.: Concentrations and sources of non-methane hydrocarbons (NMHCs) from 2005 to 2013 in Hong Kong: a 
multi-year real-time data analysis, Atmos. Environ., 103, 196206, 2015.

Ou, J. M., Yuan, Z. B., Zheng, J. Y., Huang, Z. J., Shao, M., Li, Z. K., Huang, X. B., Guo, H., and Louie, P. K. K.: Ambient ozone control in a photochemically active region: short-term despiking or long-term attainment?, Environ. Sci. Technol., 50, 5720-5728, 2016.

Pan, X., Kanaya, Y., Tanimoto, H., Inomata, S., Wang, Z., Kudo, S., and Uno, I.: Examining the major contributors of ozone pollution in a rural area of the Yangtze River Delta region during harvest season, Atmos. Chem. Phys., 15, 6101-6111, https://doi.org/10.5194/acp-15-6101-2015, 2015.

Seinfeld, J. H. and Pandis, S. N.: Atmospheric Chemistry and Physics: from air pollution to climate change, 2nd edition, Wiley Publisher, New Jersey, USA, 2006.

Shao, M., Lu, S., Liu, Y., Xie, X., Chang, C., Huang, S., and Chen, Z.: Volatile organic compounds measured in summer in Beijing and their role in ground-level ozone formation, J. Geophys. Res., 114, D00G06, https://doi.org/10.1029/2008JD010863, 2009a.

Shao, M., Zhang, Y. H., Zeng, L. M., Tang, X. Y., Zhang, J., Zhong, L. J., and Wang, B. G.: Ground-level ozone in the Pearl River Delta and the roles of $\mathrm{VOC}$ and $\mathrm{NO}_{\mathrm{x}}$ in its production, J. Environ. Manage., 90, 512-518, 2009b.

Shao, M., Wang, B., Lu, S., Yuan, B., and Wang, M.: Effects of Beijing Olympics Control Measures on Reducing Reactive Hydrocarbon Species, Environ. Sci. Technol., 45, 514-519, 2011.

Shao, P., An, J. L., Xin, J. Y., Wu, F. K., Wang, J. X., Ji, D. S., and Wang, Y. S.: Source apportionment of VOCs and the contribution to photochemical ozone formation during summer in the typical industrial area in the Yangtze River Delta, China, Atmos. Res., 176-177, 64-74, 2016.

Statistical yearbook of Nanjing: Nanjing Statistic Bureau: available at: http://221.226.86.104/file/2014/jiaotongyunshu/index. htm (last access: 29 March 2020), 2014.

Tsai, W. Y., Chan, L. Y., Blake, D. R., and Chu, K. W.: Vehicular fuel composition and atmospheric emissions in South China: Hong Kong, Macau, Guangzhou, and Zhuhai, Atmos. Chem. Phys., 6, 3281-3288, https://doi.org/10.5194/acp-6-3281-2006, 2006.

U.S. EPA: United States Environmental Protection Agency, 2017 National Emissions Inventory (NEI) data, available at: https://www.epa.gov/air-emissions-inventories/ 2017-national-emissions-inventory-nei-data (last access: 3 January 2020), 2017.

von Schneidemesser, E., Monks, P. S., and Plass-Duelmer, C.: Global comparison of VOC and $\mathrm{CO}$ observations in urban areas, Atmos. Environ., 44, 5053-5064, 2010.

Wang, H., Chen, C., Wang, Q., Huang, C., Su, L., Huang, H., Lou, S., Zhou, M., Li, L., Qiao, L., and Wang, Y.: Chemical loss of volatile organic compounds and its impact on the source analysis through a two-year continuous measurement, Atmos. Environ., 80, 488-498, 2013.

Wang, H. L., Lou, S. R., Huang, C., Qiao, L. P., Tang, X. B., Chen, C. H., Zeng, L. M., Wang, Q., Zhou, M., Lu, S. H., and Yu, X. N.: Source profiles of volatile organic compounds from biomass burning in Yangtze River Delta, China, Aerosol Air Qual. Rese., 14, 818-828, 2014.

Wang, M., Shao, M., Chen, W., Lu, S., Liu, Y., Yuan, B., Zhang, Q., Zhang, Q., Chang, C.-C., Wang, B., Zeng, L., Hu, M., Yang, Y., and Li, Y.: Trends of non-methane hydrocarbons (NMHC) emissions in Beijing during 2002-2013, Atmos. Chem. Phys., 15, 1489-1502, https://doi.org/10.5194/acp-15-1489-2015, 2015.

Wang, T., Wei, X. L., Ding, A. J., Poon, C. N., Lam, K. S., Li, Y. S., Chan, L. Y., and Anson, M.: Increasing surface ozone concentrations in the background atmosphere of Southern China, 1994-2007, Atmos. Chem. Phys., 9, 6217-6227, https://doi.org/10.5194/acp-9-6217-2009, 2009.

Warneke, C., de Gouw, J. A., Holloway, J. S., Peischl, J., Ryerson, T. B., Atlas, E., Blake, D., Trainer, M., and Parrish, D. D.: Multiyear trends in volatile organic compounds in Los Angeles, California: Five decades of decreasing emissions, J. Geophys. Res., 117, D00V17, https://doi.org/10.1029/2012JD017899, 2012.

Xia, L., Cai, C., Zhu, B., An, J., Li, Y., and Li, Y.: Source apportionment of VOCs in a suburb of Nanjing, China, in autumn and winter, J. Atmos. Chem., 71, 175-193, 2014a.

Xia, S., Zhao, Q., Li, B., and Shen, G.: Anthropogenic source VOCs emission inventory of Jiangsu Province, Res. Environ. Sci., 27, 120-126, 2014b (in Chinese).

Xu, Z. N., Huang, X., Nie, W., Chi, X. G., Xu, Z., Zheng, L. F., Sun, P., Ding, and A. J.: Influence of synoptic condition and holiday effects on VOCs and ozone production in the Yangtze River Delta region, China, Atmos. Environ., 168, 112-124, 2017.

Yuan, B., Chen, W. T., Shao, M., Wang, M., Lu, S. H., Wang, B., Liu, Y., Chang, C. C., and Wang, B: Measurements of ambient hydrocarbons and carbonyls in the Pearl River Delta (PRD), China, Atmos. Res., 116, 93-104, 2012.

Yuan, Z., Lau, A. K. H., Shao, M., Louie, P. K. K., Liu, S. C., and Zhu, T.: Source analysis of volatile organic compounds by positive matrix factorization in urban and rural environments in Beijing, J. Geophys. Res., 114, D00G15, https://doi.org/10.1029/2008JD011190, 2009.

Yuan, Z. B., Zhong, L. J., Lau, A. K. H., Yu, J. Z., and Louie, P. K. K.: Volatile organic compounds in the Pearl River Delta: identification of source regions and recommendation for emissionoriented monitoring strategies, Atmos. Environ., 76, 162-172, 2013.

Zhang, J., Wang, Y., Wu, F., Lin, H., and Wang, W.: Nonmethane hydrocarbon measurements at a suburban site in Changsha City, China. Sci. Total Environ., 408, 312-317, 2009.

Zhang, X., Xue, Z., Li, H., Yan, L., Yang, Y., Wang, Y., Duan, J., Li, L., Chai, F., Cheng, M., and Zhang, W.: Ambient volatile organic compounds pollution in China, J. Environ. Sci., 55, 69-75, 2017.

Zhang, Y. L., Wang, X. M., Blake, D. R., Li, L. F., Zhang, Z., Wang, S. Y., Guo, H., Lee, F. S. C., Gao, B., Chan, L. Y., Wu, D., and Rowland, F. S.: Aromatic hydrocarbons as ozone precursors before and after outbreak of the 2008 financial crisis in the Pearl River Delta region, south China, J. Geophys. Res., 117, D15306, https://doi.org/10.1029/2011JD017356, 2012.

Zhang, Y. L., Wang, X., Barletta, B., Simpson, I. J., Blake, D. R., Fu, X., Zhang, Z., He, Q., Liu, T., Zhao, X., and Ding, X.: Source attributions of hazardous aromatic hydrocarbons in urban, suburban and rural areas in the Pearl River Delta (PRD) region, J. Hazard. Mater., 250, 403-411, 2013.

Zhang, Y. L., Yang, W. Q., Simpson, I. J., Huang, X. Y., Yu, J. Z., Huang, Z. H., Wang, Z. Y., Zhang, Z., Liu, D., Huang, Z. Z., Wang, Y. J., Pei, C. L., Shao, M., Blake, D. R., Zheng, J. Y., and Huang, Z. J.: Decadal changes in emissions of volatile organic compounds (VOCs) from on-road vehicles with intensified au- 
tomobile pollution control: case study in a busy urban tunnel in south China, Environ. Pollut., 233, 806-819, 2018.

Zhang, Y. X., An, J. L., Wang, J. X., Shi, Y. Z., Liu, J. D., and Liang, J. S.: Source analysis of volatile organic compounds in the Nanjing industrial area and evaluation of their contribution to ozone, Environ. Sci., 39, 502-510, 2018.

Zhao, Q, Shen, G., Li, L., Chen, F., Qiao, Y. Z., Li, C. Y., Liu, Q., and Han, J. Z.: Ambient Particles $\left(\mathrm{PM}_{10}, \mathrm{PM}_{2.5}\right.$, and $\left.\mathrm{PM}_{1.0}\right)$ and $\mathrm{PM}_{2.5}$ chemical components in Western Yangtze River Delta (YRD): An Overview of Data from 1-year Online Continuous Monitoring at Nanjing, Aerosol Sci. Eng., 1, 107-118, 2017.

Zheng, J. Y., Zhong, L. J., Wang, T., Louie, P. K. K., and Li, Z. C.: Ground-level ozone in the Pearl River Delta region: analysis of data from a recently established regional air quality monitoring network, Atmos. Environ. 44, 814-823, 2010.
Zhou, D., Li, B., Huang X., Virkkula, A., Wu, H. S., Zhao, Q. Y., Zhang, J., Liu, Q., Li, L., Li, C. Y., Chen, F., Yuan, S. Y., Qiao, Y. Z., Shen, G. F., and Ding A. J.: The impacts of emission control and regional transport on $\mathrm{PM}_{2.5}$ ions and carbon components in Nanjing during the 2014 Nanjing Youth Olympic Games, Aerosol Air Qual. Res., 17, 730-740, 2017.

Zou, Y., Deng, X. J., Zhu, D., Gong, D. C., Wang, H., Li, F., Tan, H. B., Deng, T., Mai, B. R., Liu, X. T., and Wang, B. G.: Characteristics of 1 year of observational data of VOCs, $\mathrm{NO}_{x}$ and $\mathrm{O}_{3}$ at a suburban site in Guangzhou, China, Atmos. Chem. Phys., 15, 6625-6636, https://doi.org/10.5194/acp-15-6625-2015, 2015. 